\title{
Safety and Efficacy of Misoprostol and Dinoprostone as Cervical Ripening Agents
}

\author{
Shakya R, ${ }^{1}$ Shrestha J, ${ }^{2}$ Thapa $\mathrm{P}^{1}$ \\ 'Department of Pharmacy, Kathmandu University, Dhulikhel, Kavre, 'WHO and Department of Drug Administration, Kathmandu.
}

\section{ABSTRACT}

Introduction: The study compares safety and efficacy of misoprostol and dinoprostone as cervical ripening agents.

Methods: Patients with term, vertex, singleton pregnancy and Bishop score of 4 or less were randomly assigned to receive misoprostol pessary $(n=35,50 \mu \mathrm{g}$ intravaginally) or dinoprostone gel $(\mathrm{n}=31,0.5$ mg intracervically) at 6 hourly intervals. If there were no progress in cervical dilatation or effective uterine contraction even after maximum dose, patients were taken for cesarean section. Patients who achieved Bishop's score more than 7 but the delivery was not progressing, were augmented with oxytocin drip.

Results: No uterine hyperstimulation was observed in both groups. However, abnormal fetal heart rate was observed in 3(8.6\%) cases in misoprostol group and 2(6.5\%) in dinoprostone group. There was no statistically significant difference in meconium passage in two groups. Apgar score less than 7 at 1 minute was seen in 6(19.4\%) and 11(31.4\%) neonates in dinoprostone and misoprostol group respectively. However Apgar score less than 7 at 5 minutes was found in only one neonate of dinoprostone treated patient.

Both drugs were found to be equally effective in improving Bishops score with no significant difference in mean induction to delivery time. Cesarean section was done among $32.3 \%$ and $28.6 \%$ respectively in dinoprostone and misoprostol groups. There was significant reduction in the need for oxytocin augmentation in misoprostol (37.1\%) group than in dinoprostone (67.7\%) group.

Conclusions: Vaginal misoprostol is an effective, safer and cheaper alternative to dinoprostone as a cervical ripening agent in underdeveloped countries.

Key Words: Apgar score, Bishops Score, cervical ripening, Dinoprostone, induction, Misoprostol

\author{
Correspondence: \\ Ms. Rajani Shakya \\ Department of Pharmacy \\ Kathmandu University \\ Dhulikhel, Kavre, Nepal. \\ Phone: 011661399
}




\section{INTRODUCTION}

Induction of labor refers to the process whereby uterine contractions are initiated by medical or surgical means before the onset of spontaneous labor. ${ }^{1,2}$ Labor induction in the presence of an unfavorable cervix may be prolonged, tedious and eventuate in a cesarean delivery. Cervical ripening with prostaglandin agents decreases induction time and need for oxytocin. Assessment of cervical ripening is done with Bishop score (BS). Any score less than 6 recommends that a cervical ripening agent be used before labor induction. ${ }^{2-6}$

Dinoprostone has been long used for preinduction and cervical ripening and currently is the only pharmacological agent approved by the US Food and Drug Administration for this purpose. However, several trials suggest that Misoprostol, a prostaglandin (PG) $E_{1}$ analog, could be an alternative. $^{7-9}$

The study aims to compare safety and effectiveness of intravaginal misoprostol with repeated intracervical dinoprostone in women with unfavorable cervices and intact membranes.

\section{METHODS}

This is a comparative prospective interventional study conducted at Dhulikhel Hospital Kathmandu University Teaching Hospital (DH, KUTH) from March 2006 to July 2006. The study included 66 patients.

Inclusion criteria included gestational period of more than 37 weeks, indication for labor induction, BS less than or equal to 4 , intact membrane and cephalic presentation. Exclusion criteria were previous cesarean delivery, grand multiparity (more than five), breech presentation, contraindications to induction, BS of more than 4, contractions more than 3 per 10 minutes before drug administration and premature rupture of membranes (PROM).

Approval was obtained from ethical and research committee of the hospital. Subjects gave informed consent and were randomly assigned to receive either misoprostol pessary $50 \mathrm{mcg}$ per vagina ( 35 women) or $0.5 \mathrm{mg}$ of dinoprostone intracervically (31 women) in an unblinded fashion. BS, FHR and uterine contractility was assessed prior to drug administration. All patients underwent continuous FHR and uterine contraction monitoring every 15 minutes for first two hours then every 4 hours of each dosing.

Misoprostol pessary was administered every 6 hourly by the attending doctor in the posterior fornix with maximum dose of up to six. BS was reviewed continuously. In another group, dinoprostone gel was administered twice intracervically, 6hrs apart. A vaginal examination was performed before the administration of the second dose. If there were more than 3 contractions for more than 30 seconds in 10 minutes or labor had started or cervical score was 6 or more, the second dose of cervical ripening agent was not given.

Tachysystole was defined as a contraction frequency of more than five within 10 minutes for two consecutive 10 minutes period. Uterine hyperstimulation was defined as exaggerated uterine response with late FHR decelerations or fetal tachycardia greater than 160 beats per minutes or other worrisome FHR changes. An abnormal FHR pattern was defined as the presence of either fetal tachycardia, bradycardia, late decelerations, or a moderate to severe deceleration of FHR. Labor was defined as regular painful uterine contractions with cervical change or spontaneous rupture of membranes. Failed induction occurred when painful, regular contractions with cervical change were not achieved and the patient was delivered by cesarean with failed induction as sole indication. Active phase was defined as complete cervical effacement and dilatation of at least $3 \mathrm{~cm} .{ }^{15,16}$

Once in labor, women were cared for according to current obstetric practice. If there was no progress in cervical dilatation, effacement or effective contractions even after maximum dose of cervical ripening agents, patients were taken for cesarean section operation. Patients who achieved BS more than 7 but the delivery was not progressing for longer than 1 hour were augmented with oxytocin drip for maximum of 12 hours. After that, if women did not reach active phase, cesarean for failed induction was done.

The prespecified outcomes were interval from start of induction to vaginal delivery, vaginal delivery achieved within 24 hrs after randomization, change in BS, abnormalities of uterine contractility with and without FHR changes, mode of delivery, need of oxytocin augmentation, maternal morbidity and side effects (e.g., fever, chills, gastrointestinal symptoms) and short-term neonatal outcome (e.g. Apgar score, meconium passage, neonatal intensive care unit admission etc.).

Statistical analysis was done using Statistical Package for Social Sciences (SPSS) program version 11.5 using c2 square test and $Z$ test.

\section{RESULTS}

Baseline characters were similar between two groups in terms of patient's age, gestational time, parity and the preinduction BS. Thirty one patients received dinoprostone gel $0.5 \mathrm{mg}$ intracervically up to 2 doses and remaining 
35 patients received misoprostol pessary $50 \mathrm{mcg}$, intravaginally with maximum dose up to six, every six hourly. The number of doses of dinoprostone required for preinduction was $1.65 \pm 0.48$ (mean \pm S.D), and that of misoprostol was $2.14 \pm 1.2$.

Although there was increase in the BS after treatment in both groups, there was statistically insignificant difference between two groups in terms of either the change in BS after drug administration or the BS measured pre treatment (Table 1). There were no significant differences in the mode of delivery $(P=0.618)$. Ten $(32.3 \%)$ patients out of 31 from dinoprostone group and $10(28.6 \%)$ patients out of 35 from misoprostol group had cesarean delivery (Table 2).

Table 1. Comparison of change in Bishop Score

\begin{tabular}{llll}
\hline Bishop score & Dinoprostone & Misoprostol & P value \\
\hline$(\mathrm{n}=31)$ & $(\mathrm{n}=35)$ & & \\
Initial bishop score & $3.35 \pm 0.91$ & $3.00 \pm 0.90$ & 0.11 \\
After 6 hours & $5.48 \pm 2.0$ & $4.90 \pm 1.5$ & 0.22 \\
After 12 hours & $6.23 \pm 2.2$ & $6.38 \pm 1.9$ & 0.81 \\
Change in 6 hours & $2.17 \pm 2.0$ & $2.00 \pm 1.6$ & 0.72 \\
Change in 12 hours & $2.90 \pm 2.1$ & $.65 \pm 1.9$ & 0.23 \\
\hline
\end{tabular}

(Mean \pm S.D)

Table 2. Comparison of mode of delivery

\begin{tabular}{lll}
\hline Mode of delivery & \multicolumn{2}{l}{ Dinoprostone } \\
\hline & Misoprostol \\
\hline Vaginal & $21(67.7 \%)$ & (n=35) \\
Spontaneous Vaginal delivery & $21(67.5 \%)$ & $24(68.6 \%)$ \\
Assisted vaginal delivery & $0(0 \%)$ & $1(2.9 \%)$ \\
Cesarean section & $10(32.3 \%)$ & $10(28.6 \%)$ \\
\hline
\end{tabular}

Indications for cesarean section were similar: in misoprostol group, $4(40 \%)$ cesarean sections were performed for failed induction and 5(50\%) were due to fetal distress. Remaining one was due to oligohydramnios. In dinoprostone group, $5(50 \%)$ cesarean was due to failed induction and another $5(50 \%)$ was due to fetal distress.

The difference in mean induction to delivery time was not statistically significant in two groups $(17.19 \mathrm{hrs}$ in dinoprostone versus $17.99 \mathrm{hrs}$ in misoprostol group, $\mathrm{P}$ $=0.83)$. Even though $19(90.5 \%)$ out of 21 patients from dinoprostone group and 18 (72.0\%) out of 25 patients from misoprostol group delivered within 24 hours of initiation of induction, this difference was not found to be statistically significant $(P=0.42)$.

Augmentation of oxytocin was required in significantly greater number of patients in dinoprostone group than in misoprostol group (21(67.7\%) versus $13(37.1 \%), P$ $=0.013$ ). Women in the misoprostol group were much less likely to require oxytocin compared with dinoprostone group.

No cases of uterine hyperstimulation were observed in both groups. However abnormal FHR was observed in $2(6.5 \%)$ cases in dinoprostone group and $3(8.6 \%)$ cases in misoprostone group. Again there was no statistically significant difference between the two groups with regards to meconium passage $(7(22.6 \%)$ in dinoprostone group versus $8(22.9 \%)$ in misoprostol group, $P=0.97)$. Our study indicates misoprostol 50 mcg 6 hourly to be an effective preinducing agent with no major maternal side effects, such as uterine hyperstimulation or uterine rupture (Table 3 ).

Table 3. Adverse effects

\begin{tabular}{llll}
\hline Adverse effects & \multicolumn{2}{l}{ Dinoprostone Misoprostol P value } \\
\hline & $(\mathrm{n}=31)$ & $(\mathrm{n}=35)$ & \\
Hyperstimulation & $0(0 \%)$ & $0(0 \%$ & \\
Abnormal fetal heart rate & $2(6.5 \%)$ & $3(8.6 \%)$ & 0.74 \\
Meconium passage & $7(22.6 \%)$ & $8(22.9 \%)$ & 0.97 \\
\hline
\end{tabular}

Minor maternal side effects reported were nausea, vomiting and diarrhea. Two(6.5\%) patients from dinoprostone group and $3(8.6 \%)$ from misoprostol group experienced vomiting, whereas $3(8.6 \%)$ patients from misoprostol group and another $1(2.9 \%)$ patient from the same group experienced nausea and diarrhea respectively.

Birth weights of neonates were similar between groups. There was no statistically significant difference in Apgar score at 1 minute and 5 minute between two groups. One-minute Apgar score less than 7(6(19.4\%) and $11(31.4 \%)$ in dinoprostone and misoprostol group respectively) and Apgar score at 5 minutes less than 7 (1(3.2\%) in dinoprostone group) were not significantly different between misoprostol and dinoprostone groups. Supplemental oxygen requirement was 10(32.3\%) in dinoprostone group and $11(32.4 \%)$ in misoprostol group. None of the newborns required intubations, or admission to neonatal intensive care unit (Table 4).

Table 4. Comparison of Neonatal outcomes

\begin{tabular}{llll}
\hline Outcome & \multicolumn{2}{c}{$\begin{array}{c}\text { Dinoprostone Misoprostol } \\
(\mathrm{n}=31)\end{array}$} & $\begin{array}{l}\text { P value } \\
(\mathrm{n}=35)\end{array}$ \\
\hline Birth weight $(\mathrm{kg})$ & $2.76 \pm 0.41$ & $2.90 \pm 0.47$ & 0.23 \\
Apgar Score $<7$ at $1 \mathrm{~min}$ & $6(19.4 \%)$ & $11(31.4 \%)$ & 0.26 \\
Apgar Score $<7$ at $5 \mathrm{~min}$ & $1(3.2 \%)$ & $0(0 \%)$ & 0.28 \\
Supplemental oxygen & $10(32.3 \%)$ & $11(32.4 \%)$ & 0.99 \\
Neonatal Intensive Care Unit & $0(0 \%)$ & $0(0 \%)$ & \\
Neonatal mortality & $0(0 \%)$ & $0(0 \%)$ &
\end{tabular}




\section{DISCUSSION}

Misoprostol is inexpensive and is stable at room temperature than dinoprostone. However, the apparent increase in uterine hyperstimulation with or without fetal heart rate (FHR) changes and the rare but serious complication like rupture uterus are of concern. ${ }^{10-4}$ Studies to establish safety, addressing the risks of uterine hyperstimulation, uterine rupture and serious neonatal and maternal morbidity are needed.

Labor induction is one of the most commonly performed obstetric procedures, with upto $40 \%$ of all patients undergoing inpatients cervical ripening. ${ }^{17}$ Prostaglandins are highly efficacious cervical ripening agents used to shorten induction to delivery intervals, improve induction success, and reduce morbidities associated with prolonged labor induction. The use of these agents, however, is associated with the potential for uterine hyperstimulation with FHR changes. ${ }^{12-6}$ Many previous studies have proven effectiveness of misoprostol and dinoprostol for preinduction. Our study was designed to assess the safety and effectiveness of vaginal misoprostol and intracervical dinoprostone when used as cervical ripening agent. The major finding in this study was that misoprostol is as effective as dinoprostol in cervical ripening. Improvement in BS by both of these agents was comparable. One comparative study done in India showed that there was significant improvement in the BS of both group but no significant difference between two groups in mean change in $\mathrm{BS}^{18}$

Our study finding shows that there is no difference in the efficacy of the two drugs in terms of preinduction to delivery time. Number of deliveries within 12 hours of treatment initiation was also not significantly different between dinoprostol (29\%) and misoprostol (28.6\%) groups. More number of patients from dinoprostone $(61.3 \%)$ group delivered within 24 hours of treatment initiation than misoprostol (51.4\%) although this difference was found to be statistically insignificant. The preinduction to delivery time was found to be significantly shorter in misoprostol (11 vs. 18 hours) treated group in a study carried by Ramsey et al. ${ }^{21}$ However his study showed no significant difference in delivery within 24 hours between the two groups. Various studies have shown considerable variation as far as induction to delivery time is concerned ranging from 9 hours to 17.9 hours. ${ }^{19,20}$ Meta-analysis of misoprostol for cervical ripening and labor induction in eight trials including nearly 1000 women revealed that misoprostol-treated subjects had a higher incidence of vaginal delivery within 24 hours of initially receiving misoprostol and a shorter time interval from start of medication to delivery when compared with control subjects by approximately 4.5 hours. ${ }^{22}$

The present study indicates that misoprostol was associated with less need of oxytocin augmentation. Cesarean section occurred in both groups and were found to be comparable. Study done by Jose et al. found better result with oral misoprostol with less need for oxytocin augmentation and lesser cesarean section operations for failed induction. ${ }^{23}$

We didn't found any cases of hyperstimulation, uterine rupture or PROM. A Meta analysis conducted by $\mathrm{L}$ Sanchez-Ramos et al. confirmed the safety of intravaginal misoprostol with similar incidences of uterine hyperstimulation in misoprostol and control group. ${ }^{22}$

The Cochrane Pregnancy and Childbirth Group reviewed trials comparing misoprostol with placebo, oxytocin, or prostaglandin E2 for cervical ripening. ${ }^{24}$ The study showed that vaginal misoprostol (25 to $100 \mathrm{mcg}$ ) was more effective than dinoprostone for inducing vaginal delivery within 24 hours. However, uterine hyperstimulation with associated changes in the FHR was more common in women who received misoprostol than in women who received dinoprostone. No difference in the rates of cesarean delivery, serious neonatal or maternal morbidity or mortality was seen between women who received misoprostol and those who received dinoprostone.

Several studies have reported hyperstimulation and tachysystole with misoprostol. But we did not find any such cases. It may be due to the reason that others have used higher doses of misoprostol like $100 \mathrm{mcg}$ and 200 mcg whereas we have used a lower dose of $50 \mathrm{mcg}$, which might explain absence of excessive uterine activity. There is less risk of hyperstimulation with lower dose of misoprostol but also decreases the effectiveness for labor induction. $^{25,26}$ It may be seen from several studies done in the past that also the route of administration has some effect on incidence of hyperstimulation. Adair et al, ${ }^{27}$ in a randomized, double masked trial of 178 women found similar efficacy between $200 \mathrm{mcg}$ oral and $50 \mathrm{mcg}$ vaginal administration, but the oral route was associated with more frequent uterine contractility, including an unexpected high rate of hyperstimulation syndrome $(44.1 \%)$. To decrease that high rate, lower oral doses of misoprostol was used in several other studies, but the effectiveness was also lowered.

Regarding neonatal outcomes, perinatal results evaluated by means of Apgar score, birth weight, meconium stain and admission to intensive care unit were comparable between two groups. A study done in Taiwan by Chang $\mathrm{CH}$ et al have also reported similar perinatal outcome in the two groups. ${ }^{28}$ Sanchez Ramos et al. have also found that there is no difference in neonatal outcomes in both groups of patients. ${ }^{22}$

Although intravaginal dinoprostone is currently the drug of choice for labor induction, it is quite expensive and must be refrigerated to maintain its potency. When we did the comparison of cost we found that there is a significant price difference between misoprostol and dinoprostone for induction of labor. In our hospital dinoprostone is 7 times more expensive than misoprostol. The cost will be increased further if oxytocin augmentation is needed. Patrik S. Ramsey et al have also done a 
comparative study in which they have compared cost and efficacy of these two prostaglandin analogs as labor inducing agents. They have found that misoprostol is more cost effective than the comparable commercial dinoprostone as an adjuvant to labor induction in women with unfavorable cervix. ${ }^{21}$

Findings of this study suggest that the less expensive drug misoprostol is safer for mother and fetus with comparable BS and interval to vaginal delivery as dinoprostone. Although this study has not found an increase in serious morbidity or mortality with vaginal misoprostol use, the sample size was not sufficiently large enough to exclude the possibility of uncommon serious adverse effects. Potential areas of interest for misoprostol use for labor induction include oral administration and a crushed or gel form, in addition to lowering the dose and increasing the interval between administrations. Researchers can design further trials to develop the safest dose, form and route of misoprostol administration.

\section{CONCLUSIONS}

Misoprostol appears to be safe and beneficial for inducing labor in a woman with an unfavorable cervix. It is equally efficacious for cervical ripening and labor induction as dinoprostone in terms of improvement in BS.

\section{ACKNOWLEDGEMIENTS}

We would like to thank staffs of Dhulikhel Hospital, Dhulikhel for helping us.

\section{REFERENCES}

1. Normitz ER, Robinson JN, Repke TJ. Induction of labour. In: Gabbe Steven G, Niebyl RJ, Leigh Joe, editors. Obstetrics normal and problem pregnancies. US: Churchill Livingstone; 2002. p. 373.

2. Chamberlain G, Steer PJ. Turnbull's Obstetrics. $3^{\text {rd }}$ ed. UK: Harcovet; 2002.

3. National Institute for Clinical Excellence. Induction of labour. 2001 June:18

4. Crane Joan. Induction of labor at term. J Obstet Gynaecol Can. 2001;23(8):717-28.

5. Oxford Database of Perinatal Trials. Cochrane Pregnancy and Child Birth Data Base. Oxford.

6. Alberta Reproductive Health. Pregnancies and Births Table Update. AHW and Alberta Perinatal Health Program. 2005.

7. Marguilies M, Perez MC, Vato L. Misoprostol for induction of labor. Lancet. 1992;339:364.

8. Fletcher H, Mitchell S, Frederick J, Simeon D, Brown D. Intravaginal misoprostol vs. dinoprostone as cervical ripening and labor inducing agents. Obstet Gynecol. 1994;83:244-7.

9. Buser D, Mora G, Arias F. A randomized comparison between misoprostol and dinoprostone for cervical ripening and labor induction in patients with unfavorable cervices. Obstet Gynecol. 1997;89:581.

10. Gemund V, Scherjon S, Cessie S, Schagen VL, Roosmalen JV. A randomized trial comparing low dose vaginal misoprostol and dinoprostone for labour induction. BJOG. 2004;111:42.

11. Sanchez-Ramos L, Kaunitz AM, Del Valle GO, Delke I, Schroeder PA, Briones DK. Labor induction with the prostaglandin $\mathrm{E}_{1}$ methyl analogue misoprostol versus oxytocin: a randomized trial. Obstet Gynecol. 1993;81:332-6.

12. Wing DA, Jones MM, Rahall A, Goodwin TM, Paul RH. A comparison of misoprostol and prostaglandin $\mathrm{E}_{2}$ gel for preinduction cervical ripening and labor induction. Am J Obstet Gynecol. 1995;172:1804-10.

13. Wing DA, Rahall A, Jones MM, Goodwin TM, Paul RH. Misoprostol: an effective agent for cervical ripening and labor induction. Am J Obstet Gynecol. 1995;172:1811-6.

14. Fletcher HM, Mitchell S, Simeon D, Frederick J, Brown D. Intravaginal misoprostol as a cervical ripening agent. Br J Obstet Gynaecol. 1993; 100:641-4.

15. Marjorie M, Jeannie P, Do and Diantha H. Outpatient misoprostol Compared with Dinoprostool Gel for preinduction Cervical Ripening: A randomized Controlled Trial. Obstetrics and Gynecology. 2005;105:466-72.
16. Carlan SJ, Sheila B, Danielle B, Willia FO. Safety and Efficacy of Misoprostol Orally and Vaginally: A randomized Trial. Obstetrics and Gynecology. 2001;98:107-12.

17. Mitchael LS, Josheph B, Fowler M, Ghendron RT, Gherman RB. Outpatient cervical ripening with intravaginal Misoprostol. Obstetrics and Gynecology. 2000;96:684-8.

18. Sharma Y, Kumar S, Mittal S, Misra R. Evaluation of glyceryl trinitrate, misoprostol, and prostaglandin E2gel for preinduction cervical ripening in term pregnancy. J. Obstet. Gynaecol. 2005;31(3):210-5.

19. Noah ML, Decoster JM, Fraser W. Preinduction cervical softening with endocervical PGE2 gel. A multicentric trial. Acta Obstet Gynecol Scand. 1987; 66:3-7.

20. Hofmeyr GJ. Misoprostol administered vaginally for cervical ripening and labour induction in the third trimester. Cochrane Library Update Software. 1998;3.

21. Ramsey PS et al. Comparative efficacy and cost of the prostaglandin analogs dinoprostone and misoprostol as labor preinduction agents. Am J Obstet Gynecol. 2003;188(2):561.

22. Sanchez-Ramos L, Kaunitz AM, Wears RL, Delke I, Gaudier FL. Misoprostol for cervical ripening and labor induction: a metaanalysis. Obstet Gynecol. 1997;89:633-42.

23. Jose LB, Rafael CD, Fatima GB, Pilar MDF, Luis J, Moreno C. Oral misoprostol and intracervical dinoprostone for cervical ripening and labor induction: a randomized comparison. Obstet Gynecol. 2000;96:465-9.

24. Hofmeyr GJ, Gulmezoglu AM, Alfirevic Z. Misoprostol for induction of labour: a systematic review. Br J Obstet Gynaecol. 1999;106:798-803.

25. Dallenbach P, Boulvain M, Caroline V, Oliver I. Oral Misoprostol or vaginal dinoprostone for labor induction: a randomized controlled trial. Obstet Gynaecol. 2002;188:162-7.

26. Wing DA, Ham D, Paul RH. A comparison of orally administered misoprostol with vaginally administered misoprostol for cervical ripening and labor induction. Am J Gynecol. 1999;180:1155-60.

27. Adair CD, Weeks JW, Barrileaux S, Edwards M, Burlison K, Lewis DF. Oral or vaginal misoprostol administration for induction of loabor: arandomized, double-blind trial. Obstet Gynaecol. 1999;92: 810-3.

28. Chang CH, Chang FM. J Randomized comparison of misoprostol and dinoprostone for preinduction cervical ripening and labor induction. Formos Med Assoc. 1997;96:366-9.

\section{\begin{tabular}{l|l|l|l|l|l|} 
JNMA & VIL 49 & Na. 1 & ISSUE & 177 & JAN-MAR, 2010
\end{tabular}}

